Supporting Information

\title{
Binding of Organophosphorus Nerve Agents and Their Simulants to Metal Salts
}

Jake Gold ${ }^{1}$,Tibor Szilvási ${ }^{1}$, Nicholas L. Abbott ${ }^{2}$,Manos Mavrikakis ${ }^{1, *}$

${ }^{1}$ Department of Chemical and Biological Engineering University of Wisconsin - Madison, Madison, WI 53706

${ }^{2}$ School of Chemical and Biomolecular Engineering, Cornell University, Ithaca, NY 14853

*Corresponding author: Manos Mavrikakis (emavrikakis@wisc.edu) 


\section{$\underline{\text { Analyte Binding Free Energy to Metal-Perchlorate Salts }}$}

\begin{tabular}{|c|c|c|c|c|c|c|c|c|c|c|c|}
\hline & MDCP & $\mathrm{DMCP}$ & $\mathrm{GA}$ & GD & GB & TMP & VX & DMMP & DIMP & $\left\langle\mathrm{G}_{\mathrm{BE}}\right\rangle_{\mathrm{A}, \mathrm{P}}$ & $\square^{-0.20}$ \\
\hline $\mathrm{Al}^{3+}$ & -0.69 & -0.80 & -0.90 & -0.99 & -1.08 & -1.15 & -1.28 & -1.34 & -1.40 & -1.07 & \multirow{7}{*}{ 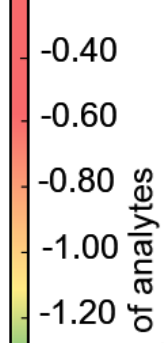 } \\
\hline $\mathrm{Cd}^{2+}$ & -0.81 & -0.97 & -1.00 & -1.03 & -1.05 & -1.19 & -1.31 & -1.28 & -1.35 & -1.11 & \\
\hline $\mathrm{Co}^{2+}$ & -0.88 & -1.01 & -1.11 & -1.25 & -1.25 & -1.31 & -1.33 & -1.37 & -1.46 & -1.22 & \\
\hline $\mathrm{Cr}^{3+}$ & -0.53 & -0.66 & -0.72 & -0.80 & -0.76 & -0.97 & -1.01 & -1.01 & -1.14 & -0.85 & \\
\hline $\mathrm{Cu}^{2+}$ & -0.58 & -0.68 & -0.62 & -0.74 & -0.89 & -0.85 & -1.01 & -1.08 & -1.06 & -0.83 & \\
\hline $\mathrm{Fe}^{3+}$ & -0.69 & -0.92 & -1.00 & -0.94 & -1.02 & -1.25 & -1.16 & -1.37 & -1.33 & -1.07 & \\
\hline $\mathrm{Ga}^{3+}$ & -0.55 & -0.88 & -0.85 & -1.05 & -0.95 & -1.07 & -1.28 & -1.30 & -1.35 & -1.03 & \\
\hline $\mathrm{La}^{3+}$ & -1.08 & -1.30 & -1.24 & -1.36 & -1.32 & -1.57 & -1.56 & -1.71 & -1.80 & -1.44 & \\
\hline $\mathrm{Mn}^{2+}$ & -0.99 & -1.11 & -1.12 & -1.21 & -1.28 & -1.31 & -1.45 & -1.41 & -1.49 & -1.26 & \\
\hline $\mathrm{Ni}^{2+}$ & -0.89 & -1.01 & -1.12 & -1.19 & -1.18 & -1.21 & -1.20 & -1.32 & -1.43 & -1.17 & -1.60 \\
\hline $\mathrm{Sc}^{3+}$ & -0.94 & -1.00 & -1.24 & -1.30 & -1.31 & -1.53 & -1.58 & -1.62 & -1.82 & -1.37 & \\
\hline $\mathrm{Zn}^{2+}$ & -0.93 & -1.10 & -1.10 & -1.23 & -1.27 & -1.29 & -1.46 & -1.37 & -1.52 & -1.25 & \\
\hline$\left\langle\mathrm{G}_{\mathrm{BE}}\right\rangle_{\mathrm{C}, \mathrm{P}}$ & -0.80 & -0.95 & -1.00 & -1.09 & -1.11 & -1.23 & -1.30 & -1.35 & -1.43 & -1.14 & -2.00 \\
\hline
\end{tabular}

Figure S1. Calculated binding free energy $\left(\mathrm{G}_{\mathrm{BE}}\right.$; in $\mathrm{eV}$ ) for a total of nine analytes (NAs and NA simulants) on metal-perchlorate salts. The color scale demonstrates the relative strength of adsorption and ranges from red (weak binding) to green (strong binding), with yellow in between. NAs and NA simulants are arranged from left to right according to increasing $\mathrm{G}_{\mathrm{BE}}$ averaged over all metal cations (bottommost row, $\left\langle\mathrm{G}_{\mathrm{BE}}\right\rangle_{\mathrm{C}, \mathrm{P}}$ ). The cations are arranged from top to bottom by increasing $G_{\mathrm{BE}}$ averaged over all analytes (rightmost column, $\left.<\mathrm{G}_{\mathrm{BE}}\right\rangle_{\mathrm{A}, \mathrm{P}}$ ).

Analyte Binding Free Energy to Metal-Nitrate Salts

\begin{tabular}{|c|c|c|c|c|c|c|c|c|c|c|c|}
\hline & MDCP & DMCP & GA & GB & GD & TMP & DMMP & VX & DIMP & $\left\langle G_{B E}\right\rangle_{A, N}$ & $\Pi^{-0.20}$ \\
\hline $\mathrm{Al}^{3+}$ & -0.20 & -0.43 & -0.45 & -0.44 & -0.44 & -0.56 & -0.72 & -0.75 & -0.75 & -0.53 & \\
\hline $\mathrm{Cd}^{2+}$ & -0.55 & -0.72 & -0.78 & -0.80 & -0.79 & -0.84 & -0.95 & -0.99 & -1.01 & -0.83 & \\
\hline $\mathrm{Co}^{2+}$ & -0.60 & -0.76 & -0.90 & -0.87 & -0.90 & -0.98 & -1.04 & -1.06 & -1.03 & -0.91 & -0.60 \\
\hline $\mathrm{Cr}^{3+}$ & -0.20 & -0.39 & -0.40 & -0.45 & -0.43 & -0.55 & -0.66 & -0.66 & -0.83 & -0.51 & $-0.80 \stackrel{0}{\sim}$ \\
\hline $\mathrm{Cu}^{2+}$ & -0.39 & -0.51 & -0.57 & -0.57 & -0.56 & -0.64 & -0.75 & -0.68 & -0.74 & -0.60 & \\
\hline $\mathrm{Fe}^{3+}$ & -0.57 & -0.71 & -0.84 & -0.83 & -0.88 & -0.95 & -1.03 & -1.04 & -1.23 & -0.90 & \\
\hline $\mathrm{Ga}^{3+}$ & -0.21 & -0.40 & -0.48 & -0.46 & -0.52 & -0.64 & -0.77 & -0.73 & -0.94 & -0.57 & \\
\hline $\mathrm{La}^{3+}$ & -0.78 & -0.91 & -1.03 & -1.01 & -0.98 & -1.15 & -1.30 & -1.33 & -1.39 & -1.10 & \\
\hline $\mathrm{Mn}^{2+}$ & -0.74 & -0.87 & -0.94 & -0.98 & -1.00 & -0.99 & -1.19 & -1.18 & -1.13 & -1.00 & \\
\hline $\mathrm{Ni}^{2+}$ & -0.72 & -0.86 & -0.78 & -0.89 & -0.91 & -1.02 & -1.08 & -1.14 & -1.18 & -0.95 & -1.60 \\
\hline $\mathrm{Sc}^{3+}$ & -0.72 & -0.87 & -1.03 & -1.10 & -1.06 & -1.02 & -1.26 & -1.26 & -1.47 & -1.09 & \\
\hline $\mathrm{Zn}^{2+}$ & -0.65 & -0.77 & -0.82 & -0.88 & -0.92 & -0.97 & -1.05 & -1.08 & -1.09 & -0.91 & \\
\hline $\mathrm{G}_{\mathrm{BE}}>\mathrm{C} \mathrm{CN}$ & -0.53 & -0.68 & -0.75 & -0.77 & -0.78 & -0.86 & -0.98 & -0.99 & -1.07 & -0.82 & -2.00 \\
\hline
\end{tabular}

Figure S2. Calculated binding free energy $\left(\mathrm{G}_{\mathrm{BE}}\right.$; in $\mathrm{eV}$ ) for a total of nine analytes (NAs and NA simulants) on metal-nitrate salts. The color scale demonstrates the relative strength of adsorption and ranges from red (weak binding) to green (strong binding), with yellow in between. NAs and NA simulants are arranged from left to right according to increasing $\mathrm{G}_{\mathrm{BE}}$ averaged over all metal cations (bottommost row, $\left\langle\mathrm{G}_{\mathrm{BE}}\right\rangle_{\mathrm{C}, \mathrm{N}}$ ). The cations are arranged from top to bottom by alphabetical order of atomic symbols. 
(a)

\begin{tabular}{|c|c|c|c|c|}
\hline & $5 \mathrm{CB}$ & $\mathrm{PM}$ & $\mathrm{PD}$ & $\left\langle\mathrm{G}_{\mathrm{BE}}\right\rangle_{\mathrm{A}, \mathrm{P}}$ \\
\hline $\mathrm{Al}^{3+}$ & -0.43 & -0.59 & -0.80 & -0.60 \\
\hline $\mathrm{Cd}^{2+}$ & -0.83 & -0.96 & -1.12 & -0.97 \\
\hline $\mathrm{Co}^{2+}$ & -0.78 & -1.03 & -1.17 & -0.99 \\
\hline $\mathrm{Cr}^{3+}$ & -0.45 & -0.65 & -0.82 & -0.64 \\
\hline $\mathrm{Cu}^{2+}$ & -0.56 & -0.78 & -0.95 & -0.77 \\
\hline $\mathrm{Fe}^{3+}$ & -0.34 & -0.77 & -0.94 & -0.68 \\
\hline $\mathrm{Ga}^{3+}$ & -0.53 & -0.81 & -1.00 & -0.78 \\
\hline $\mathrm{La}^{3+}$ & -0.86 & -0.88 & -1.00 & -0.91 \\
\hline $\mathrm{Mn}^{2+}$ & -0.83 & -0.99 & -1.15 & -0.99 \\
\hline $\mathrm{Ni}^{2+}$ & -0.85 & -1.16 & -1.31 & -1.11 \\
\hline $\mathrm{Sc}^{3+}$ & -0.75 & -0.83 & -1.00 & -0.86 \\
\hline $\mathrm{Zn}^{2+}$ & -0.89 & -1.11 & -1.28 & -1.09 \\
\hline$\left\langle\mathrm{G}_{\mathrm{BE}}{ }^{2+} \mathrm{C}, \mathrm{P}\right.$ & -0.68 & -0.88 & -1.04 & -0.87 \\
\hline
\end{tabular}

Mesogen Binding Free Energy to Metal-Perchlorate (a) and -Nitrate (b) Salts (b)

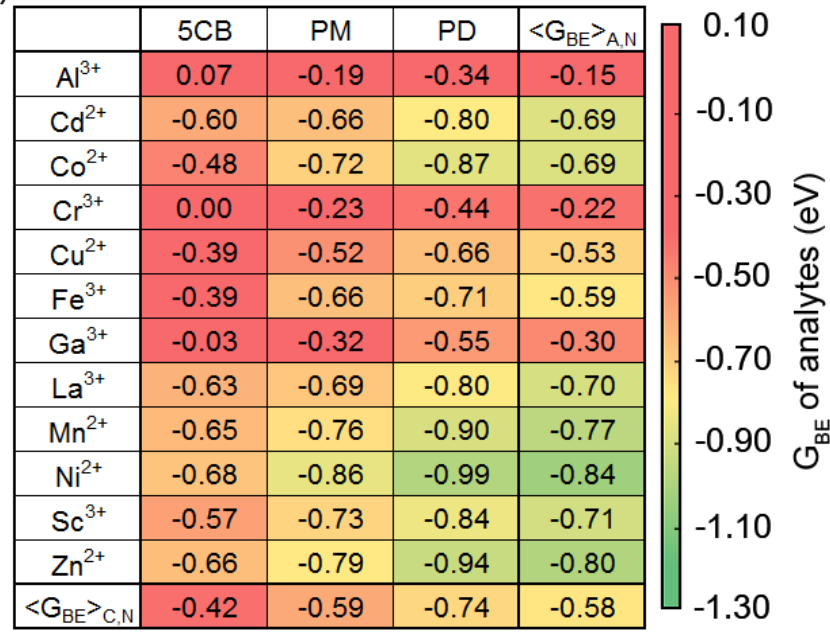

Figure S3. Calculated binding Gibbs free energy $\left(\mathrm{G}_{\mathrm{BE}}\right.$; in $\left.\mathrm{eV}\right)$ for a total of three mesogens on (a) metalperchlorate and (b) metal-nitrate salts. DFT calculations were performed with the surrogate molecules benzonitrile, pyrimidine, and pyridine for 5CB, PM, and PD, respectively. Color scale ranges from red (weak binding) to green (strong binding) and yellow in between. Note that the color scales are the same for perchlorates and nitrate salts. Mesogens are arranged from left to right by increasing average $\mathrm{G}_{\mathrm{BE}}$ averaged over all metal cations (bottommost row, (a) $\left\langle\mathrm{G}_{\mathrm{BE}}>_{\mathrm{C}, \mathrm{P}}\right.$ and (b) $\left\langle\mathrm{G}_{\mathrm{BE}}\right\rangle_{\mathrm{C}, \mathrm{N}}$ ). The cations are arranged from top to bottom by alphabetical order of atomic symbols. 
Analyte Displacement Free Energy for Metal-Perchlorate Salts with Respect to $\underline{5 \mathrm{CB}}$

\begin{tabular}{|c|c|c|c|c|c|c|c|c|c|}
\hline & MDCP & DMCP & GA & GD & GB & TMP & $v x$ & DMMP & DIMP \\
\hline $\mathrm{Al}^{3+}$ & -0.26 & -0.37 & -0.47 & -0.56 & -0.66 & -0.72 & -0.86 & -0.91 & -0.98 \\
\hline $\mathrm{Cd}^{2+}$ & 0.02 & -0.14 & -0.17 & -0.20 & -0.22 & -0.36 & -0.48 & -0.45 & -0.52 \\
\hline $\mathrm{Co}^{2+}$ & -0.10 & -0.23 & -0.33 & -0.47 & -0.46 & -0.52 & -0.55 & -0.59 & -0.68 \\
\hline $\mathrm{Cr}^{3+}$ & -0.08 & -0.22 & -0.27 & -0.35 & -0.31 & -0.52 & -0.56 & -0.56 & -0.69 \\
\hline $\mathrm{Cu}^{2+}$ & -0.01 & -0.12 & -0.06 & -0.17 & -0.32 & -0.28 & -0.45 & -0.52 & -0.50 \\
\hline $\mathrm{Fe}^{3+}$ & -0.35 & -0.57 & -0.66 & -0.60 & -0.68 & -0.91 & -0.82 & -1.03 & -0.99 \\
\hline $\mathrm{Ga}^{3+}$ & -0.02 & -0.35 & -0.32 & -0.52 & -0.42 & -0.54 & -0.75 & -0.77 & -0.81 \\
\hline $\mathrm{La}^{3+}$ & -0.21 & -0.43 & -0.37 & -0.49 & -0.46 & -0.71 & -0.69 & -0.85 & -0.94 \\
\hline $\mathrm{Mn}^{2+}$ & -0.16 & -0.27 & -0.28 & -0.37 & -0.44 & -0.48 & -0.61 & -0.57 & -0.66 \\
\hline $\mathrm{Ni}^{2+}$ & -0.04 & -0.15 & -0.27 & -0.33 & -0.32 & -0.36 & -0.35 & -0.47 & -0.57 \\
\hline $\mathrm{Sc}^{3+}$ & -0.18 & -0.25 & -0.48 & -0.55 & -0.56 & -0.78 & -0.82 & -0.87 & -1.07 \\
\hline $\mathrm{Zn}^{2+}$ & -0.04 & -0.21 & -0.21 & -0.34 & -0.39 & -0.40 & -0.57 & -0.48 & -0.63 \\
\hline$\left\langle\mathrm{G}_{\mathrm{DE}}\right\rangle_{\mathrm{C}, \mathrm{P}}$ & -0.12 & -0.28 & -0.32 & -0.41 & -0.44 & -0.55 & -0.63 & -0.67 & -0.75 \\
\hline \multicolumn{10}{|c|}{$\mathrm{G}_{\mathrm{DE}}$ of analytes $(\mathrm{eV})$} \\
\hline 0.45 & 0.25 & 0.05 & -0.1 & & & & -0.75 & -0.95 & -1.15 \\
\hline
\end{tabular}

Figure S4. Calculated displacement Gibbs free energies $\left(\mathrm{G}_{\mathrm{DE}} ; \mathrm{eV}\right)$ for a total of nine analytes (NAs and NA simulants) on metal-perchlorate salts with respect to $5 \mathrm{CB}$. The color scale ranges from red (no displacement is predicted) to green (fast displacement is predicted), while yellow represents intermediate values of $\mathrm{G}_{\mathrm{DE}}$ where displacement is still possible. NAs and NA simulants are ordered from left to right according to increasing $\mathrm{G}_{\mathrm{DE}}$ averaged over all metal cations (bottommost row, $\left\langle\mathrm{G}_{\mathrm{DE}}\right\rangle_{\mathrm{C}, \mathrm{P}}$ ). Note that it can be proven from the definition of average $G_{D E}$ and average $G_{B E}$ that the arrangement of analytes in this table must follow the same trend as being arranged by average $\mathrm{G}_{\mathrm{BE}}$ of metal-perchlorate salts in Figure $\mathrm{S} 1$. The cations are arranged from top to bottom by alphabetical order of atomic symbols. 
Analyte Displacement Free Energy for Metal-Nitrate Salts with Respect to $\underline{5 \mathrm{CB}}$

\begin{tabular}{|c|c|c|c|c|c|c|c|c|c|}
\hline & $\mathrm{MDCP}$ & $\mathrm{DMCP}$ & GA & GB & GD & TMP & DMMP & $V X$ & DIMP \\
\hline $\mathrm{Al}^{3+}$ & -0.28 & -0.50 & -0.52 & -0.51 & -0.52 & -0.64 & -0.79 & -0.83 & -0.83 \\
\hline $\mathrm{Cd}^{2+}$ & 0.05 & -0.13 & -0.18 & -0.21 & -0.19 & -0.24 & -0.35 & -0.40 & -0.41 \\
\hline $\mathrm{Co}^{2+}$ & -0.12 & -0.28 & -0.42 & -0.39 & -0.42 & -0.50 & -0.56 & -0.58 & -0.55 \\
\hline $\mathrm{Cr}^{3+}$ & -0.20 & -0.39 & -0.40 & -0.45 & -0.43 & -0.56 & -0.66 & -0.66 & -0.83 \\
\hline $\mathrm{Cu}^{2+}$ & 0.00 & -0.12 & -0.18 & -0.18 & -0.17 & -0.25 & -0.36 & -0.29 & -0.35 \\
\hline $\mathrm{Fe}^{3+}$ & -0.18 & -0.32 & -0.45 & -0.44 & -0.49 & -0.56 & -0.63 & -0.65 & -0.84 \\
\hline $\mathrm{Ga}^{3+}$ & -0.19 & -0.37 & -0.45 & -0.43 & -0.49 & -0.61 & -0.74 & -0.71 & -0.91 \\
\hline $\mathrm{La}^{3+}$ & -0.15 & -0.28 & -0.41 & -0.39 & -0.36 & -0.53 & -0.67 & -0.71 & -0.76 \\
\hline $\mathrm{Mn}^{2+}$ & -0.10 & -0.23 & -0.30 & -0.33 & -0.35 & -0.34 & -0.54 & -0.53 & -0.49 \\
\hline $\mathrm{Ni}^{2+}$ & -0.04 & -0.18 & -0.11 & -0.21 & -0.24 & -0.34 & -0.41 & -0.46 & -0.50 \\
\hline $\mathrm{Sc}^{3+}$ & -0.15 & -0.30 & -0.45 & -0.53 & -0.49 & -0.45 & -0.69 & -0.68 & -0.90 \\
\hline $\mathrm{Zn}^{2+}$ & 0.01 & -0.11 & -0.16 & -0.22 & -0.26 & -0.31 & -0.39 & -0.42 & -0.43 \\
\hline$\left\langle\mathrm{G}_{\mathrm{DE}}\right\rangle_{\mathrm{C}, \mathrm{N}}$ & -0.11 & -0.27 & -0.34 & -0.36 & -0.37 & -0.44 & -0.57 & -0.58 & -0.65 \\
\hline \multicolumn{10}{|c|}{$\mathrm{G}_{\mathrm{DE}}$ of analytes (eV) } \\
\hline 0.45 & 0.25 & 0.05 & -0.1 & & & 55 & -0.75 & -0.95 & -1.15 \\
\hline
\end{tabular}

Figure S5. Calculated displacement Gibbs free energies $\left(\mathrm{G}_{\mathrm{DE}} ; \mathrm{eV}\right)$ for a total of nine analytes (NAs and NA simulants) on metal-nitrate salts with respect to 5CB. The color scale ranges from red (no displacement is predicted) to green (fast displacement is predicted), while yellow represents intermediate values of $\mathrm{G}_{\mathrm{DE}}$ where displacement is still possible. NAs and NA simulants are ordered from left to right according to increasing $\mathrm{G}_{\mathrm{DE}}$ averaged over all metal cations (bottommost row, $\left\langle\mathrm{G}_{\mathrm{DE}}\right\rangle_{\mathrm{C}, \mathrm{N}}$ ). Note that it can be proven from the definition of average $G_{D E}$ and average $G_{B E}$ that the arrangement of analytes in this table must follow the same trend as being arranged by average $\mathrm{G}_{\mathrm{BE}}$ of metal-nitrate salts in Figure $\mathrm{S} 2$. The cations are arranged from top to bottom by alphabetical order of atomic symbols. 


\section{Analyte Displacement Free Energy for Metal-Perchlorate Salts with Respect to $\underline{P M}$}

\begin{tabular}{|c|c|c|c|c|c|c|c|c|c|}
\hline & MDCP & DMCP & GA & GD & GB & TMP & $v x$ & DMMP & DIMP \\
\hline $\mathrm{Al}^{3+}$ & -0.10 & -0.21 & -0.31 & -0.40 & -0.50 & -0.56 & -0.70 & -0.75 & -0.82 \\
\hline $\mathrm{Cd}^{2+}$ & 0.15 & -0.01 & -0.04 & -0.07 & -0.09 & -0.23 & -0.36 & -0.33 & -0.39 \\
\hline $\mathrm{Co}^{2 *}$ & 0.14 & 0.01 & -0.09 & -0.22 & -0.22 & -0.28 & -0.30 & -0.35 & -0.44 \\
\hline $\mathrm{Cr}^{3 *}$ & 0.12 & -0.01 & -0.07 & -0.15 & -0.11 & -0.32 & -0.36 & -0.36 & -0.49 \\
\hline $\mathrm{Cu}^{2+}$ & 0.20 & 0.09 & 0.16 & 0.04 & -0.11 & -0.07 & -0.24 & -0.31 & -0.28 \\
\hline $\mathrm{Fe}^{3 *}$ & 0.07 & -0.15 & -0.23 & -0.17 & -0.25 & -0.48 & -0.39 & -0.60 & -0.56 \\
\hline $\mathrm{Ga}^{3+}$ & 0.26 & -0.07 & -0.04 & -0.24 & -0.14 & -0.27 & -0.48 & -0.49 & -0.54 \\
\hline $\mathrm{La}^{3+}$ & -0.20 & -0.42 & -0.36 & -0.48 & -0.44 & -0.69 & -0.68 & -0.83 & -0.93 \\
\hline $\mathrm{Mn}^{2+}$ & 0.00 & -0.12 & -0.13 & -0.22 & -0.29 & -0.32 & -0.46 & -0.42 & -0.50 \\
\hline $\mathrm{Ni}^{2 *}$ & 0.27 & 0.15 & 0.03 & -0.03 & -0.02 & -0.06 & -0.04 & -0.17 & -0.27 \\
\hline $\mathrm{Sc}^{3+}$ & -0.10 & -0.17 & -0.40 & -0.47 & -0.48 & -0.70 & -0.74 & -0.79 & -0.99 \\
\hline $\mathrm{Zn}^{2+}$ & 0.18 & 0.02 & 0.02 & -0.12 & -0.16 & -0.18 & -0.35 & -0.26 & -0.41 \\
\hline$\left\langle G_{D E}\right\rangle_{C, P}$ & 0.08 & -0.07 & -0.12 & -0.21 & -0.23 & -0.35 & -0.42 & -0.47 & -0.55 \\
\hline \multicolumn{10}{|c|}{$\mathrm{G}_{\mathrm{DE}}$ of analytes (eV) } \\
\hline 0.45 & 0.25 & 0.05 & -0.1 & \multicolumn{2}{|c|}{-0.35} & -0.55 & -0.75 & -0.95 & -1.1 \\
\hline
\end{tabular}

Figure S6. Calculated displacement Gibbs free energies $\left(\mathrm{G}_{\mathrm{DE}} ; \mathrm{eV}\right)$ for a total of nine analytes (NAs and NA simulants) on metal-perchlorate salts with respect to PM. The color scale ranges from red (no displacement is predicted) to green (fast displacement is predicted), while yellow represents intermediate values of $\mathrm{G}_{\mathrm{DE}}$ where displacement is still possible. NAs and NA simulants are ordered from left to right according to increasing $G_{D E}$ averaged over all metal cations (bottommost row, $\left\langle\mathrm{G}_{\mathrm{DE}}\right\rangle_{\mathrm{C}, \mathrm{P}}$ ). Note that it can be proven from the definition of average $G_{D E}$ and average $G_{B E}$ that the arrangement of analytes in this table must follow the same trend as being arranged by average $G_{\mathrm{BE}}$ of metal-perchlorate salts in Figure $S 1$. The cations are arranged from top to bottom by alphabetical order of atomic symbols. 
Analyte Displacement Free Energy for Metal-Nitrate Salts with Respect to $\underline{\text { PM }}$

\begin{tabular}{|c|c|c|c|c|c|c|c|c|c|}
\cline { 2 - 11 } \multicolumn{1}{c|}{} & MDCP & DMCP & GA & GB & GD & TMP & DMMP & VX & DIMP \\
\hline $\mathrm{Al}^{3+}$ & -0.02 & -0.24 & -0.26 & -0.25 & -0.26 & -0.38 & -0.53 & -0.57 & -0.57 \\
\hline $\mathrm{Cd}^{2+}$ & 0.11 & -0.06 & -0.12 & -0.14 & -0.13 & -0.17 & -0.28 & -0.33 & -0.34 \\
\hline $\mathrm{Co}^{2+}$ & 0.11 & -0.05 & -0.18 & -0.15 & -0.18 & -0.26 & -0.32 & -0.34 & -0.32 \\
\hline $\mathrm{Cr}^{3+}$ & 0.04 & -0.16 & -0.17 & -0.22 & -0.20 & -0.32 & -0.43 & -0.43 & -0.60 \\
\hline $\mathrm{Cu}^{2+}$ & 0.13 & 0.01 & -0.05 & -0.04 & -0.04 & -0.12 & -0.23 & -0.16 & -0.22 \\
\hline $\mathrm{Fe}^{3+}$ & 0.09 & -0.05 & -0.18 & -0.17 & -0.21 & -0.28 & -0.36 & -0.38 & -0.57 \\
\hline $\mathrm{Ga}^{3+}$ & 0.10 & -0.09 & -0.16 & -0.14 & -0.20 & -0.32 & -0.45 & -0.42 & -0.62 \\
\hline $\mathrm{La}^{3+}$ & -0.09 & -0.22 & -0.35 & -0.33 & -0.29 & -0.47 & -0.61 & -0.65 & -0.70 \\
\hline $\mathrm{Mn}^{2+}$ & 0.02 & -0.11 & -0.18 & -0.22 & -0.24 & -0.22 & -0.42 & -0.42 & -0.37 \\
\hline $\mathrm{Ni}^{2+}$ & 0.14 & 0.00 & 0.08 & -0.03 & -0.06 & -0.16 & -0.22 & -0.28 & -0.32 \\
\hline $\mathrm{Sc}^{3+}$ & 0.01 & -0.14 & -0.30 & -0.37 & -0.33 & -0.29 & -0.53 & -0.53 & -0.74 \\
\hline $\mathrm{Zn}^{2+}$ & 0.15 & 0.02 & -0.03 & -0.09 & -0.13 & -0.18 & -0.26 & -0.29 & -0.30 \\
\hline$\left\langle\mathrm{G}_{\mathrm{DE}}{ }^{2+} \mathrm{C}, \mathrm{N}\right.$ & 0.07 & -0.09 & -0.16 & -0.18 & -0.19 & -0.26 & -0.39 & -0.40 & -0.47 \\
\hline
\end{tabular}

Figure S7 Calculated displacement Gibbs free energies $\left(\mathrm{G}_{\mathrm{DE}} ; \mathrm{eV}\right)$ for a total of nine analytes (NAs and NA simulants) on metal-nitrate salts with respect to PM. The color scale ranges from red (no displacement is predicted) to green (fast displacement is predicted), while yellow represents intermediate values of $\mathrm{G}_{\mathrm{DE}}$ where displacement is still possible. NAs and NA simulants are ordered from left to right according to increasing $\mathrm{G}_{\mathrm{DE}}$ averaged over all metal cations (bottommost row, $\left\langle\mathrm{G}_{\mathrm{DE}}\right\rangle_{\mathrm{C}, \mathrm{N}}$ ). Note that it can be proven from the definition of average $G_{D E}$ and average $G_{B E}$ that the arrangement of analytes in this table must follow the same trend as being arranged by average $\mathrm{G}_{\mathrm{BE}}$ of metal-nitrate salts in Figure $\mathrm{S} 2$. The cations are arranged from top to bottom by alphabetical order of atomic symbols. 


\section{Analyte Displacement Free Energy for Metal-Perchlorate Salts with Respect to $\underline{\mathrm{PD}}$}

\begin{tabular}{|c|c|c|c|c|c|c|c|c|c|}
\hline & MDCP & DMCP & GA & GD & GB & TMP & $V x$ & DMMP & DIMP \\
\hline $\mathrm{Al}^{3 *}$ & 0.11 & 0.00 & -0.10 & -0.19 & -0.29 & -0.35 & -0.49 & -0.54 & -0.61 \\
\hline $\mathrm{Cd}^{2+}$ & 0.30 & 0.15 & 0.12 & 0.09 & 0.06 & -0.07 & -0.20 & -0.17 & -0.24 \\
\hline $\mathrm{Co}^{2 *}$ & 0.29 & 0.16 & 0.06 & -0.07 & -0.07 & -0.13 & -0.15 & -0.20 & -0.29 \\
\hline $\mathrm{Cr}^{3 *}$ & 0.29 & 0.16 & 0.10 & 0.02 & 0.06 & -0.15 & -0.19 & -0.19 & -0.32 \\
\hline $\mathrm{Cu}^{2+}$ & 0.38 & 0.27 & 0.33 & 0.22 & 0.07 & 0.11 & -0.06 & -0.13 & -0.11 \\
\hline $\mathrm{Fe}^{3+}$ & 0.25 & 0.02 & -0.06 & 0.00 & -0.08 & -0.31 & -0.22 & -0.43 & -0.39 \\
\hline $\mathrm{Ga}^{3+}$ & 0.45 & 0.12 & 0.15 & -0.05 & 0.04 & -0.08 & -0.29 & -0.30 & -0.35 \\
\hline $\mathrm{La}^{3+}$ & -0.08 & -0.29 & -0.24 & -0.36 & -0.32 & -0.57 & -0.56 & -0.71 & -0.80 \\
\hline $\mathrm{Mn}^{2+}$ & 0.16 & 0.05 & 0.04 & -0.05 & -0.12 & -0.16 & -0.29 & -0.25 & -0.34 \\
\hline $\mathrm{Ni}^{2 *}$ & 0.42 & 0.30 & 0.18 & 0.12 & 0.13 & 0.10 & 0.11 & -0.01 & -0.12 \\
\hline $\mathrm{Sc}^{3+}$ & 0.06 & 0.00 & -0.24 & -0.31 & -0.31 & -0.54 & -0.58 & -0.63 & -0.82 \\
\hline $\mathrm{Zn}^{2+}$ & 0.35 & 0.18 & 0.18 & 0.05 & 0.00 & -0.02 & -0.18 & -0.10 & -0.24 \\
\hline$\left\langle G_{D E}\right\rangle_{C, P}$ & 0.25 & 0.09 & 0.04 & -0.04 & -0.07 & -0.18 & -0.26 & -0.30 & -0.38 \\
\hline \multicolumn{10}{|c|}{$\mathrm{G}_{\mathrm{DE}}$ of analytes $(\mathrm{eV})$} \\
\hline 0.45 & 0.25 & 0.05 & -0.1 & & & & -0.75 & -0.95 & -1.15 \\
\hline
\end{tabular}

Figure S8. Calculated displacement Gibbs free energies $\left(\mathrm{G}_{\mathrm{DE}} ; \mathrm{eV}\right)$ for a total of nine analytes (NAs and NA simulants) on metal-perchlorate salts with respect to PD. The color scale ranges from red (no displacement is predicted) to green (fast displacement is predicted), while yellow represents intermediate values of $\mathrm{G}_{\mathrm{DE}}$ where displacement is still possible. NAs and NA simulants are ordered from left to right according to increasing $\mathrm{G}_{\mathrm{DE}}$ averaged over all metal cations (bottommost row, $\left\langle\mathrm{G}_{\mathrm{DE}}\right\rangle_{\mathrm{C}, \mathrm{P}}$ ). Note that it can be proven from the definition of average $G_{D E}$ and average $G_{B E}$ that the arrangement of analytes in this table must follow the same trend as being arranged by average $G_{\mathrm{BE}}$ of metal-perchlorate salts in Figure $\mathrm{S} 1$. The cations are arranged from top to bottom by alphabetical order of atomic symbols. 
Analyte Displacement Free Energy for Metal-Nitrate Salts with Respect to $\underline{\mathrm{PD}}$

\begin{tabular}{|c|c|c|c|c|c|c|c|c|c|}
\hline & MDCP & $\mathrm{DMCP}$ & GA & GB & GD & TMP & DMMP & VX & DIMP \\
\hline $\mathrm{Al}^{3 *}$ & 0.13 & -0.09 & -0.11 & -0.10 & -0.10 & -0.23 & -0.38 & -0.42 & -0.42 \\
\hline $\mathrm{Cd}^{2+}$ & 0.25 & 0.08 & 0.02 & -0.01 & 0.01 & -0.04 & -0.15 & -0.19 & -0.21 \\
\hline $\mathrm{Co}^{2 *}$ & 0.27 & 0.11 & -0.03 & 0.00 & -0.03 & -0.11 & -0.17 & -0.19 & -0.16 \\
\hline $\mathrm{Cr}^{3 *}$ & 0.24 & 0.04 & 0.04 & -0.02 & 0.01 & -0.12 & -0.23 & -0.23 & -0.40 \\
\hline $\mathrm{Cu}^{2+}$ & 0.27 & 0.15 & 0.10 & 0.10 & 0.10 & 0.02 & -0.09 & -0.02 & -0.07 \\
\hline $\mathrm{Fe}^{3+}$ & 0.14 & 0.00 & -0.13 & -0.12 & -0.17 & -0.24 & -0.32 & -0.33 & -0.52 \\
\hline $\mathrm{Ga}^{3+}$ & 0.34 & 0.15 & 0.07 & 0.09 & 0.03 & -0.09 & -0.22 & -0.18 & -0.39 \\
\hline $\mathrm{La}^{3+}$ & 0.02 & -0.11 & -0.23 & -0.21 & -0.18 & -0.35 & -0.50 & -0.53 & -0.59 \\
\hline $\mathrm{Mn}^{2+}$ & 0.16 & 0.03 & -0.04 & -0.08 & -0.10 & -0.09 & -0.29 & -0.28 & -0.24 \\
\hline $\mathrm{Ni}^{2 *}$ & 0.27 & 0.13 & 0.21 & 0.10 & 0.08 & -0.03 & -0.09 & -0.15 & -0.19 \\
\hline $\mathrm{Sc}^{3+}$ & 0.12 & -0.03 & -0.18 & -0.26 & -0.22 & -0.17 & -0.42 & -0.41 & -0.63 \\
\hline $\mathrm{Zn}^{2+}$ & 0.29 & 0.17 & 0.11 & 0.06 & 0.02 & -0.03 & -0.11 & -0.15 & -0.15 \\
\hline$\left\langle\mathrm{G}_{\mathrm{DE}}\right\rangle_{\mathrm{C}, \mathrm{N}}$ & 0.21 & 0.05 & -0.02 & -0.04 & -0.05 & -0.12 & -0.25 & -0.26 & -0.33 \\
\hline \multicolumn{10}{|c|}{$\mathrm{G}_{\mathrm{DE}}$ of analytes $(\mathrm{eV})$} \\
\hline 0.45 & 0.25 & 0.05 & -0.1 & & & .55 & -0.75 & -0.95 & -1.15 \\
\hline
\end{tabular}

Figure S9. Calculated displacement Gibbs free energies $\left(\mathrm{G}_{\mathrm{DE}} ; \mathrm{eV}\right)$ for a total of nine analytes (NAs and NA simulants) on metal-nitrate salts with respect to PD. The color scale ranges from red (no displacement is predicted) to green (fast displacement is predicted), while yellow represents intermediate values of $G_{\mathrm{DE}}$ where displacement is still possible. NAs and NA simulants are ordered from left to right according to increasing $\mathrm{G}_{\mathrm{DE}}$ averaged over all metal cations (bottommost row, $\left\langle\mathrm{G}_{\mathrm{DE}}\right\rangle_{\mathrm{C}, \mathrm{N}}$ ). Note that it can be proven from the definition of average $G_{D E}$ and average $G_{B E}$ that the arrangement of analytes in this table must follow the same trend as being arranged by average $\mathrm{G}_{\mathrm{BE}}$ of metal-nitrate salts in Figure $\mathrm{S} 2$. The cations are arranged from top to bottom by alphabetical order of atomic symbols. 


\section{Validity of Neutral Anion Model (NAM)}

In this section, we assess the validity of the Neutral Anion Model (NAM) against environmental factors such as humidity and solvation in the liquid crystal film. The NAM is a cluster model with one metal cation bonded to enough anions to make the overall charge neutral. Therefore, this cluster NAM has the same stoichiometric composition as the global composition of the solid metal salts used in our experiments. It is important to emphasize that this model was developed based on theoretical considerations rather than stability calculations presented in this section. NAM has been shown to be successful in describing many experimental trends for detection of NA simulants with chemoresponsive liquid crystals (see references provided in the main text).

For Tables S1-S3 (corresponding to Equations S1, S3, and S5), we also report values including a polarizable continuum model (PCM) using parameters for benzonitrile to include the effects of a solvent. We model the solvent with benzonitrile parameters because of its structural similarity to the liquid crystal 5CB. We apply the solvation model to Equations S1, S3, and S5 below to both sides of the equation. We note that this represents a computationally efficient, but simplified approach to account for solvation effects.

Table S1 reports the calculated Gibbs free energy to infinitely separate one $\mathrm{ClO}_{4}^{-}$ion from the NAM metal salt cluster. These calculations are performed based on the stoichiometry in Equation $\mathrm{S} 1$ where Me stands for the metal cation with charge $\mathrm{x}$. We tabulate these reaction free energies (Equation S2) for perchlorate salts in Table S1 where negative values correspond to an exergonic reaction. We find that for calculations in vacuum (middle column $\Delta \mathrm{G}$ in Table $\mathrm{S} 1$ ) the free energy required to separate an anion is endergonic and very large in magnitude $(\Delta \mathrm{G}>6.9 \mathrm{eV})$. Including the effect of solvation in 5CB by using a PCM with parameters of benzonitrile to both sides of the equation (as the solvent), we find that the reaction energy (for S2) is much more favored in general with $\Delta \mathrm{G}_{\mathrm{PCM}}<3.5 \mathrm{eV}$ for all the studied cases. We find that $\Delta \mathrm{G}_{\mathrm{PCM}}$ is negative for some cases suggesting that reaction $\mathrm{S} 1$ may be favored under solvent conditions: $\mathrm{Cd}^{2+}\left(\Delta \mathrm{G}_{\mathrm{PCM}}=-0.04 \mathrm{eV}\right)$, $\mathrm{La}^{3+}\left(\Delta \mathrm{G}_{\mathrm{PCM}}=-0.48 \mathrm{eV}\right)$, and $\mathrm{Mn}^{2+}\left(\Delta \mathrm{G}_{\mathrm{PCM}}=-0.10 \mathrm{eV}\right)$. In general, we find the descriptor defined in Equation $\mathrm{S} 2$ to be very positive with values as high as $\Delta \mathrm{G}_{\mathrm{PCM}}=3.14 \mathrm{eV}$ for $\mathrm{Al}^{3+}$, which suggests that most of these metal salts are stable under dry solvent conditions.

$$
\begin{aligned}
& \mathrm{Me}\left(\mathrm{ClO}_{4}\right)_{\mathrm{x}} \rightarrow \mathrm{Me}\left(\mathrm{ClO}_{4}\right)_{\mathrm{x}-1}^{1+}+\mathrm{ClO}_{4}^{-} \\
& \Delta \mathrm{G}=\mathrm{G}_{\mathrm{Me}\left(\mathrm{ClO}_{4}\right)_{\mathrm{x}-1}^{1+}}+\mathrm{G}_{\mathrm{ClO}_{4}^{-}}-\mathrm{G}_{\mathrm{Me}\left(\mathrm{ClO}_{4}\right)_{\mathrm{x}}}
\end{aligned}
$$


Table S1. Calculated Gibbs free energy of dissociating one perchlorate ion from the metal perchlorate salt cluster as described in Equation S2. The reaction Gibbs free energy in the middle column $(\Delta G)$ is calculated using the same level of theory as described in the methods section (M06-2X-D3/def2-TZVP//PBE-D3/def2-SVP) of the main text, which is the same as all values reported in Figures S1-S9. The values in the rightmost column $\left(\Delta G_{\mathrm{PCM}}\right)$ corresponds to a similar level of theory, but we add Polarizable Continuum Model (PCM) to M06-2X-D3 single point calculations to model the solvation effects using benzonitrile parameters for the solvent. All values are calculated at $298.15 \mathrm{~K}$ and $1 \mathrm{~atm}$ pressure.

\begin{tabular}{|c|c|c|}
\hline Cation & $\Delta \mathrm{G}(\mathrm{eV})$ & $\Delta \mathrm{G}_{\mathrm{PCM}}(\mathrm{eV})$ \\
\hline $\mathrm{Al}^{3+}$ & 7.33 & 3.14 \\
\hline $\mathrm{Cd}^{2+}$ & 7.30 & -0.04 \\
\hline $\mathrm{Co}^{2+}$ & 7.85 & 0.74 \\
\hline $\mathrm{Cr}^{3+}$ & 7.73 & 3.47 \\
\hline $\mathrm{Cu}^{2+}$ & 7.86 & 0.55 \\
\hline $\mathrm{Fe}^{3+}$ & 7.33 & 2.85 \\
\hline $\mathrm{Ga}^{3+}$ & 7.11 & 2.80 \\
\hline $\mathrm{La}^{3+}$ & 6.93 & -0.48 \\
\hline $\mathrm{Mn}^{2+}$ & 7.57 & -0.10 \\
\hline $\mathrm{Ni}^{2+}$ & 8.09 & 1.71 \\
\hline $\mathrm{Sc}^{3+}$ & 7.53 & 2.56 \\
\hline $\mathrm{Zn}^{2+}$ & 7.97 & 0.05 \\
\hline
\end{tabular}

In the next few tables, we attempt to assess the impact of humidity (water) on the NAM.

Table S2 reports the calculated Gibbs free energy to displace one perchlorate ion with a gas-phase water molecule. These calculations are performed using the stoichiometry defined in Equation S3, where Me stands for the metal cation with charge $\mathrm{x}$. We tabulate these reaction Gibbs free energies (Equation S4) for perchlorate salts in Table S2 where negative values correspond to an exergonic reaction. We find that under vacuum conditions (middle column $\Delta \mathrm{G}$ in Table S2), such displacement is not favored with displacement energies greater than $5 \mathrm{eV}$ for all cases. We then assessed solvation effects using PCM (see above), with benzonitrile parameters for the solvent, we find that displacement is generally more favored with all values $\Delta \mathrm{G}_{\mathrm{PCM}}<1.7 \mathrm{eV}$. In all cases, however, displacement remains endergonic, except for the case of $\mathrm{La}^{3+}$ with PCM, where we find that displacement is exergonic $\left(\Delta \mathrm{G}_{\mathrm{PCM}}=-0.41 \mathrm{eV}\right)$. However, for this case we should also consider the Gibbs free energy of binding of water to $\mathrm{La}^{3+}\left(\Delta \mathrm{G}_{\mathrm{BE}}=-0.76 \mathrm{eV}\right)$, which is more negative than $\Delta \mathrm{G}_{\mathrm{PCM}}$ for $\mathrm{La}^{3+}(-0.41 \mathrm{eV})$. This means that co-adsorption of water and the perchlorate anion is still more favored than displacement of the perchlorate anion by a water molecule.

$\mathrm{Me}\left(\mathrm{ClO}_{4}\right)_{\mathrm{x}}+\mathrm{H}_{2} \mathrm{O} \rightarrow \mathrm{Me}\left(\mathrm{H}_{2} \mathrm{O}\right)\left(\mathrm{ClO}_{4}\right)_{\mathrm{x}-1}{ }^{1+}+\mathrm{ClO}_{4}^{-}$

$\Delta \mathrm{G}=\mathrm{G}_{\mathrm{Me}\left(\mathrm{H}_{2} \mathrm{O}\right)\left(\mathrm{ClO}_{4}\right)_{\mathrm{x}-1}^{1+}}+\mathrm{G}_{\mathrm{ClO}_{4}^{-}}-\mathrm{G}_{\mathrm{Me}\left(\mathrm{ClO}_{4}\right)_{\mathrm{x}}}-\mathrm{G}_{\mathrm{H}_{2} \mathrm{O}}$ 
Table S2. Calculated Gibbs free energy of displacing one perchlorate ion from the metal perchlorate salts by a water molecule as described in Equation S4. The reaction Gibbs free energy in the middle column $(\Delta G)$ is calculated using the same level of theory as described in the methods section (M06-2X-D3/def2-TZVP//PBE-D3/def2-SVP) of the main text, which is the same as all values reported in Figures S1-S9. The values in the rightmost column $\left(\Delta \mathbf{G}_{\mathrm{PCM}}\right)$ corresponds to a similar level of theory, but we add Polarizable Continuum Model (PCM) to M06-2X-D3 single point calculations to model the solvation effects using benzonitrile parameters. All values are calculated at $298.15 \mathrm{~K}$ and $1 \mathrm{~atm}$ pressure.

\begin{tabular}{|c|c|c|}
\hline Cation & $\Delta \mathrm{G}(\mathrm{eV})$ & $\Delta \mathrm{G}_{\mathrm{PCM}}(\mathrm{eV})$ \\
\hline $\mathrm{Al}^{3+}$ & 5.48 & 1.29 \\
\hline $\mathrm{Cd}^{2+}$ & 5.44 & 0.17 \\
\hline $\mathrm{Co}^{2+}$ & 5.61 & 0.50 \\
\hline $\mathrm{Cr}^{3+}$ & 5.96 & 1.66 \\
\hline $\mathrm{Cu}^{2+}$ & 5.82 & 0.93 \\
\hline $\mathrm{Fe}^{3+}$ & 5.58 & 1.35 \\
\hline $\mathrm{Ga}^{3+}$ & 5.43 & 1.23 \\
\hline $\mathrm{La}^{3+}$ & 5.50 & -0.41 \\
\hline $\mathrm{Mn}^{2+}$ & 5.63 & 0.32 \\
\hline $\mathrm{Ni}^{2+}$ & 5.84 & 0.93 \\
\hline $\mathrm{Sc}^{3+}$ & 5.80 & 1.46 \\
\hline $\mathrm{Zn}^{2+}$ & 5.60 & 0.43 \\
\hline
\end{tabular}

A second possible impact of water is that it can bind and dissociate at the metal center to form a hydroxyl group. Table S3 reports the calculated Gibbs free energy to displace a perchlorate ion with a deprotonated water and to protonate a perchlorate ion that leaves the metal center. These calculations are performed using the stoichiometry defined in Equation S5 where Me stands for the metal cation with charge $\mathrm{x}$. We tabulate these reaction free energies (Equation S6) for perchlorate salts in Table S3 where negative values correspond to an exergonic reaction. We find for all values calculated in vacuum (middle column $\Delta \mathrm{G}$ in Table $\mathrm{S} 3$ ) to be more positive than 0.3 $\mathrm{eV}$ indicating this reaction is not favored. If we include the influence of solvent using the PCM with benzonitrile (right column $\Delta \mathrm{G}_{\mathrm{PCM}}$ in Table S3), we find a small stabilizing effect. However, all values for $\Delta \mathrm{G}_{\mathrm{PCM}}$ are still positive, indicating hydroxylation of the NAM center is not favored. Because these hydroxy ligands are less stable than the NAM, the question of how hydroxyl ligands influence the $\mathrm{G}_{\mathrm{BE}}$ is not too relevant to the experimental conditions.

$\mathrm{Me}\left(\mathrm{ClO}_{4}\right)_{\mathrm{x}}+\mathrm{H}_{2} \mathrm{O} \rightarrow \mathrm{Me}(\mathrm{OH})\left(\mathrm{ClO}_{4}\right)_{\mathrm{x}-1}+\mathrm{HClO}_{4}$

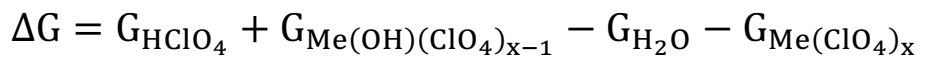


Table S3. Calculated Gibbs free energy of displacing one perchlorate ion with a deprotonated water from the metal perchlorate salts as described in Equation S6. The reaction Gibbs free energy in the middle column $(\Delta G)$ is calculated using the same level of theory as described in the methods section (M06-2X-D3/def2-TZVP//PBE-D3/def2-SVP) of the main text, which is the same as all values reported in Figures S1-S9. The values in the rightmost column $\left(\Delta G_{\mathrm{PCM}}\right)$ corresponds to a similar level of theory, but we add Polarizable Continuum Model (PCM) to M06-2X-D3 single point calculations to model the solvation effects using benzonitrile parameters. All values are calculated at $298.15 \mathrm{~K}$ and $1 \mathrm{~atm}$ pressure.

\begin{tabular}{|c|c|c|}
\hline Cation & $\Delta \mathrm{G}(\mathrm{eV})$ & $\Delta \mathrm{G}_{\mathrm{PCM}}(\mathrm{eV})$ \\
\hline $\mathrm{Al}^{3+}$ & 0.53 & 0.45 \\
\hline $\mathrm{Cd}^{2+}$ & 1.00 & 0.75 \\
\hline $\mathrm{Co}^{2+}$ & 1.11 & 1.00 \\
\hline $\mathrm{Cr}^{3+}$ & 0.96 & 0.81 \\
\hline $\mathrm{Cu}^{2+}$ & 1.21 & 1.19 \\
\hline $\mathrm{Fe}^{3+}$ & 0.47 & 0.34 \\
\hline $\mathrm{Ga}^{3+}$ & 0.38 & 0.28 \\
\hline $\mathrm{La}^{3+}$ & 0.87 & 0.58 \\
\hline $\mathrm{Mn}^{2+}$ & 1.23 & 0.89 \\
\hline $\mathrm{Ni}^{2+}$ & 1.09 & 0.92 \\
\hline $\mathrm{Sc}^{3+}$ & 0.68 & 0.55 \\
\hline $\mathrm{Zn}^{2+}$ & 0.87 & 0.56 \\
\hline
\end{tabular}

